\title{
China and the World in a Changing Context-A Brazilian Perspective
}

\author{
Paulo Estivallet de Mesquita
}

China's breathtaking transformation has seen its GDP increase from less than two percent of the world total in 1979 to close to $17 \%$ in 2020 , while its share of world trade has grown from less than one percent to more than $13 \%$ in the last 40 years. It became the world's largest economy in terms of purchasing-power parity (PPP) at least five years ago and will soon be the largest in nominal terms. The rescue of hundreds of millions of people from poverty is also a remarkable achievement. Health, longevity, education, and income: The Chinese people enjoy life today in a way that would have been hard to imagine a few decades ago. This is a tectonic development, unprecedented in scale and speed, which is having a profound impact in the world.

China's development must be applauded, and not just by its own people. Its capacity to supply large volumes of goods at low prices has allowed millions of consumers to adopt new technologies more quickly than ever before. World economic growth is higher because of Chinese consumption, investment, and savings. It is estimated that a third of world economic growth in the coming years will still come from China.

However, even though Chinese development has mostly been a force for good, it has also been disruptive. Chinese competition in manufactures has exerted considerable pressure on other countries, leading to considerable dislocation. Brazil and other developing countries suffered the first impact; as China moved up the value-added ladder, developed countries also have had to deal with this challenge, sometimes through old-fashioned protectionism.

The sheer magnitude of China's economy and its rate of economic growth also have an outsized impact on the environment. This is a matter of concern to all, though the answer obviously does not lie in denying it the right to development. China's per capita GDP is still slightly below the world average, and it understandably aspires to levels of welfare similar to more developed countries. The recent emphasis on energy efficiency and on combating pollution is welcome. China's size may also help find

P. E. de Mesquita ( $\square)$

Embassy of the Federative Republic of Brazil to the People's Republic of China, Beijing, China

(C) The Author(s) 2022

H. Wang and L. Miao (eds.), China and the World in a Changing Context,

China and Globalization, https://doi.org/10.1007/978-981-16-8086-1_24 
the solutions to some of the problems caused by its economic growth. For instance, its scale of production has brought forward a reduction in the cost of renewable energy equipment much faster than initially forecast, to the point that solar and wind energy have become competitive with fossil fuels much earlier than foreseen until recently.

China has become an inescapable fixture of the international system. Everybody pays attention to what it does. It will have to engage further, and on more issues, than ever before. With time, the international order will gradually incorporate more elements and features that reflect China's culture, interests, and actions. This will inevitably generate some friction. There are many possible outcomes, which range from positive-sum to negative-sum. It is unrealistic to expect China to quietly fulfill the expectations and desires of others. It is just as unrealistic to expect the world simply to give way to China. The world and China have to engage in a spirit of compromise, with a genuine commitment to bridging the gap in mutual knowledge and understanding, and seeking to understand each other's perspectives and aspirations.

An old football saying tells us that one should not make changes to a winning team, and China has certainly been doing very well. However, there are also countless examples of champions that failed precisely for lack of change; players get older, and adversaries learn how to counter their moves. Past performance is no guarantee of future results. China knows this well, as demonstrated by the evolution of its development strategies over the years. Adapting foreign policy is also necessary, though arguably more difficult, among other things because of the need to take into account the reactions and perceptions of others. Besides, China may also argue that it is not the only one that has to make changes.

A crucial area for engagement is international organizations. We cannot solve pressing issues like climate change or transnational crime within the confines of the jurisdiction of each nation state; even the largest ones. The number of issues that require, or at least would benefit from, concerted international efforts is certain to increase. A good example is COVID-19. The world would be in a much better place if information had flowed more smoothly, without politicization, and if there had been better international coordination for the development of vaccines. It would have made sense to pool resources to jointly finance $R \& D$ and production of vaccines, irrespective of nationality. That this idea barely made it out of academic circles says much about the state of multilateral cooperation.

Multilateral rule making had its heyday in the 1990s. Back then, the belief in the possibility of a harmonious international system was at the origin of a long series of world conferences to address some of the most pressing issues faced by the international community: the environment, human rights, hunger, gender issues, population, human settlements, and natural disasters. That tide ebbed at the turn of the century; since then, multilateral diplomacy has faced challenges across many fronts. There has been a resurgence in conflicts of perception about the international order, which are harder to manage than mere conflicts of interest because of a lack of common understanding about the premises of the debate. 
The rise of China and other Asian countries with different political traditions has made the functioning of the international system more complex. It is not the only factor, though. There is an important political current, across many countries, which believes that the rise of trans-border phenomena, with the corresponding loss of sovereign control over domestic policies, is simply the result of political choices, not technological, sociological, or demographic change.

It is interesting to note today's contrasting approaches to multilateral organizations. Usually, the rising power is the revisionist, while the established power is averse to change. Yet China has become very conservative with regard to multilateral reform. In contrast, the United States, which played the largest role in shaping international organizations and regimes, has been the most vocal proponent of change, sometimes to the point of disrupting their functioning, or even withdrawing from some of them.

It is unfair to expect China to remain a rule-taker, while at the same time accepting responsibilities in line with its current standing and capabilities. China is not the root cause of the ills of multilateralism. Progress was scarce, and results proved elusive well before China had become so prominent. The Doha Round of WTO negotiations, for instance, stalled at a time when the Chinese economy was much smaller than it is today, and China was still implementing the commitments agreed in its Protocol of Accession.

There may be arrangements and groupings that exclude China, but China has become a large part of everything, including the problems, and it has to be part of the solutions. For instance, well over half the world's countries have China as their largest trading partner; it is difficult to imagine an international trade regime without it. China registers the largest number of patents every year. It has the capacity and the resources to act as a stabilizer of financial and supply shocks. Besides, like-mindedness is not sufficient for agreement.

On the other hand, China cannot just sit back and treat multilateralism as a given, or something to pick and choose. Even if existing multilateral rules were agreed to at some point, the passage of time and changes in circumstances alter the perceived balance of rights and obligations. It does not matter whether the cause was hard work, technological breakthroughs, misfortune, or plain luck. International commitments have to be perceived as legitimate, but legitimacy is subjective and shifting. Countries comply with international agreements because they feel it is in their interest to accept limitations to their policy space in exchange for limitations to the policy space of others. If the rules start working less well, countries are confronted, as Hirschman describes it, with the choice of "exit"-i.e., withdrawal—and "voice"i.e., attempts to improve the system. When the road for improvement is closed, there is a corresponding increase in pressures to withdraw, partly or completely.

China views itself as a developing country and believes that it should not be penalized for its hard-earned success. Indeed, it still faces many challenges of development, including poverty. Its GDP per capita, after all, is still below the world average. It is, however, the world's largest trader, and it will soon become the largest economy in nominal terms. It is a developing country, but the concept of special and differential treatment (S\&D) is no longer fully suitable when applied to such a large player. S\&D provides exceptions to general rules; if those rules do not apply to the 
largest players, they are no longer "general". In fact, S\&D has mostly worked as an exemption for countries that had, at the same time, difficulty complying with and benefiting from the basic rules. It is a nod to the needs of developing countries, not a meaningful unilateral concession, and definitely not a free lunch.

Ultimately, it all comes back to the balance of rights and obligations. This is not to say that China's needs and circumstances will not be taken into account. On the contrary, international agreements are full of detailed provisions tailored to the specific needs and interests of developed countries. In the course of negotiations, China is entitled to, and capable of, obtaining the same benefits.

As in so many instances, there may well be a cultural issue here. It is not uncommon to see in the West the use of the preamble to laws and international agreements for symbolic messages that are not entirely in line with the actual content and direction of the rules. They are often used for "virtue signaling". That is why Westerners are sometimes baffled by the lack of specificity in China's policy guidelines. China could benefit, in its own interest, from learning to play a different game, paying less attention to the preamble and focusing more on the operational clauses. This is what developed countries have done throughout history: load the preambles with symbolic messages, and drive a hard bargain for the operational clauses.

China may feel no sense of urgency about reform because it has done so well under the current system. It may also have reasons to be skeptical about revisionist proposals, which it may feel are aimed at it. It is easier to be conservative and to beat the drum of respect for existing rules. Nevertheless, China will also suffer from a loss of confidence in multilateralism. Its skepticism may be self-fulfilling, and conservatism may lead to the long-term decline of multilateralism.

If we are to succeed, however, we should also be clear about large differences in perception and institutions. Multilateral regimes do not imply harmonization, but there must be mutual recognition that rules operate in a roughly equivalent manner.

The manner in which China deals with information, compounded by cultural differences, often makes it difficult for foreigners to know that rules will be applied in a consistent and timely manner. This is another instance where there have been shortcomings in communication and understanding between China and its partners. This is a recurrent problem for trade and investment. Although most business is conducted smoothly, there are many cases where operations are delayed due to the lack of a license from unspecified authorities. Reviews are undertaken by "ad hoc" committees, created in an "ad hoc" manner. It is difficult to quantify the impact of these occurrences, but they are frequent enough to generate a feeling of unpredictability and lack of transparency, which in turn feeds the narrative about imbalances in the WTO, for example.

There is also room for improvement with regard to transparency in the application of law. International rules should be predictable and applied as consistently as possible. China has made many advances in recent years, especially on commercial issues and intellectual property. The concept of "rule by law", however, is sufficiently different from the "rule of law" to be an issue in international law. Other countries do not always feel confident that rule by law will not undermine international commitments or give rise to discrimination. Of course, China is entitled to decide how it 
governs itself. It is important, however, that its partners understand clearly the content and extent of Chinese commitments under international agreements.

The Chinese system and its approach to transparency also have implications for multilateral rule making. Until now, China has not always been as proactive as it could in multilateral negotiations, although it has shown a sense of responsibility and made very substantial commitments, including on environmental issues. The decision to make the Chinese economy carbon neutral by 2060, for instance, is a major contribution to combat climate change. It is even more striking in light of the role of coal in the Chinese energy matrix. However, these decisions are often made unilaterally, and Chinese authorities make a point of stressing that they are not made because of international pressure. This preference for waiting to see what others will do before committing itself reduces China's influence, because it cannot use its own offers as leverage to improve the level of overall commitments. Staying on the sidelines, working to reduce its mandatory commitments, will not be compensated by unilateral, larger contributions at a later stage.

This may be a reflection of how Chinese decision-making works and of the domestic need to avoid the perception of bowing to international impositions. The workings of the Chinese government are often inscrutable to foreigners, and once decisions are made, they are difficult to change. China does not have to conform to the expectations of other countries, but it could do more to explain its vision of multilateral diplomacy. A collation of unilateral commitments from different countries, no matter how well intended, will lead to sub-optimal results.

As mentioned above, China is not the source of all of the problems in multilateralism, and it cannot solve those problems alone. Indeed, China might well ask what it would get in return for making changes to how it operates in order to improve its interaction with multilateral institutions and the world at large.

Historically, the best moments of multilateral cooperation have arisen after major conflicts, when the prospect of disaster helped to focus attention on what is essential. We now need a resurgence of multilateralism at a time when there are many more actors and less tolerance for hegemonism. It will not be easy, but transnational issues cannot be swept under the rug. We must all hope and work for a revival of multilateralism; if it happens, China will inevitably be a key part of it.

Multilateralism, at its best, produces the most efficient results. Multilateral rule making, however, is inefficient, because it relies on consensus. While working to improve multilateral cooperation, we must also move forward wherever and whenever possible. Brazil will continue to work with China to strengthen and diversify our bilateral relationship. We have already reaped excellent results, especially in the last two decades. We have the advantage of a lot of mutual interest and sympathy to start with, and no historical baggage to drag us down.

Bilateral trade started in the 1970s with Chinese oil exports to Brazil. China's rapid growth and the discovery of vast oil deposits in Brazil later caused a reversal in that trade. In 2020, Brazil was the fourth largest supplier of oil to China. Brazil is one of the world's largest agricultural exporters and has the largest potential for sustainable expansion of production. It is a reliable supplier of large volumes of high quality, competitively priced food products. China's impact on commodity prices 
since the beginning of this century has had a positive impact on Brazil's external accounts and has enabled major investments in transportation infrastructure in Brazil. Chinese demand has been a driver of Brazilian agricultural competitiveness, which in turn contributes to China's food security. In 2020, Brazil was China's main supplier of agricultural goods. A reduction of international trade tensions might cause some adjustments, but are unlikely to lead to a reversal. On the contrary, there will likely be an increase in the number of products and in the value added of Brazilian agricultural exports to China.

Brazil has also benefited from large Chinese investments in recent years. In addition to investment in infrastructure, closely related to the commodities trade, Chinese manufacturing and services companies have also found a large and promising market in Brazil.

There is, however, a marked disparity between trade and investment relations, based on complementarity, and more modest results in other areas, such as science and technology, cultural exchanges, and tourism. There are promising initiatives and results in some areas, but we still have a long journey ahead of us. In order to develop the full potential of bilateral relations, and in order to move from a complementary to an encompassing relationship, it is necessary to promote a considerable expansion of mutual exchanges involving the private sector, think tanks, academia, students, and tourists. There are many more students of Mandarin in Brazil and Portuguese in China than just a few years ago, but the numbers will have to increase substantially in the coming years. This will help counter the natural tendency to try to fit others into simplified categories. Unless we develop a much wider interface, our mutual perceptions will be based on stereotypes, often fashioned by third parties. We need to reach a much higher level of interaction, with more intense and diversified peopleto-people contacts. This should not be controversial, but it will take time and will require determination and support from public institutions.

Better communication will also improve what is already working, like trade and investment. In the past, trade and finance required intermediaries; direct links have made our links much easier and more profitable. The pace of development is unrelenting; new opportunities arise all the time, just as some traditional industries lose momentum. Our bilateral economic relationship has reached a level that would have been difficult to imagine two decades ago. We know it will grow larger, but it would be foolhardy to predict what it will look like in detail. We must offer the conditions for both societies to get closer to each other and to benefit from the relationship for their own national development.

Brazil and China are both large, diverse and complex countries, with many disparities, challenges, and achievements. Neither country is perfect, but both have much to offer and to gain from closer and broader contacts. Our people want to enjoy healthy, meaningful, happy lives. Their goals, aspirations and experiences are reflected in myriad cultural expressions-music, dance, literature, and popular festivals. Contrary to what Tolstoy said, we can be happy in different ways. We can learn from each other's fight against the causes of unhappiness, such as poverty. Learning how other people search for their own happiness helps us understand their humanity and thereby promote peace and understanding. 
Brazil and China have a mature relationship and a solid friendship. We have many good stories to tell each other. We have to work together to find the way to make those stories available and accessible to more Brazilians and Chinese.

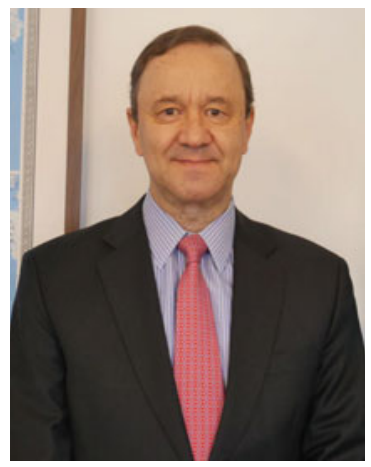

H.E. Mr. Paulo Estivallet de Mesquita is the ambassador of the Federative Republic of Brazil to the People's Republic of China. He is a Brazilian career diplomat. He holds a BSc in Agricultural Sciences from the Federal University of Rio Grande do Sul and is a graduate of Instituto Rio Branco, the Brazilian diplomatic academy. He also studied at the École Nationale d'Administration in Paris. He has worked at the Embassies of Brazil in Rome and Santiago, and at the Permanent Mission of Brazil to the WTO in Geneva. Before his arrival in Beijing, he was Undersecretary General for Latin America and the Caribbean at the Ministry for External Relations. He has been Ambassador of the Federative Republic of Brazil to the People's Republic of China since 2018.

Open Access This chapter is licensed under the terms of the Creative Commons AttributionNonCommercial-NoDerivatives 4.0 International License (http://creativecommons.org/licenses/bync-nd/4.0/), which permits any noncommercial use, sharing, distribution and reproduction in any medium or format, as long as you give appropriate credit to the original author(s) and the source, provide a link to the Creative Commons license and indicate if you modified the licensed material. You do not have permission under this license to share adapted material derived from this chapter or parts of it.

The images or other third party material in this chapter are included in the chapter's Creative Commons license, unless indicated otherwise in a credit line to the material. If material is not included in the chapter's Creative Commons license and your intended use is not permitted by statutory regulation or exceeds the permitted use, you will need to obtain permission directly from the copyright holder.

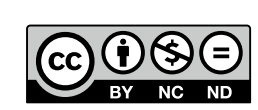

